\title{
Analisis Performansi Jaringan Indihome Fiber di Purwokerto
}

\section{Performance Analysis of Indihome Fiber Network in Purwokerto}

\author{
Pramusinta Clara Suryandari ${ }^{1 *}$, Imam Muhammadi Pradono Budi ${ }^{2}$, Fauza Khair ${ }^{3}$ \\ ${ }^{1,2,3}$ Fakultas Teknik Telekomunikasi dan Elektro, Institut Teknologi Telkom Purwokerto \\ Jl. D. I. Panjaitan No. 128 Purwokerto 53147, Jawa Tengah - Indonesia \\ 1, *Penulis Korespondensi: 13101070@ittelkom-pwt.ac.id \\ ${ }^{2}$ imam@ittelkom-pwt.ac.id, ${ }^{3}$ fauza.khair@ittelkom-pwt.ac.id
}

Received on 17-01-2020, accepted on 20-10-2020, published on 31-01-2021

\begin{abstract}
Abstrak
FTTH merupakan teknologi jaringan menggunakan kabel serat optik sebagai media transmisinya. Jaringan FTTH pada indihome sering terjadi gangguan. Oleh karena itu, penelitian ini dilakukan dengan perhitungan performansi pada parameter link budget dengan 5 sample pelanggan dan perhitungan availability dengan data SLG (Service Level Guarantee) untuk layanan triple play. Layanan voice diperoleh dari data SLG pada telepon, layanan video diperoleh dari data SLG pada IPTV dan layanan data diperoleh dari data SLG pada internet. Analisis performansi menggunakan metode perhitungan link budget dengan standar ITU-T G.984 dimana sensitivitas $-28 \mathrm{dBm}$ dan availability batas minimal standar dari PT. Telkom 95\%. Hasil perhitungan menunjukkan bahwa daerah Berkoh yang merupakan pelanggan dengan jarak terjauh dari 5 sample perhitungan daya terima diperoleh $(-24,014) \mathrm{dBm}$ untuk downlink dan $(-28,297) \mathrm{dBm}$ untuk uplink. Perhitungan margin daya didapat hasil 3,986 dBm untuk downlink dan $(-0,297) \mathrm{dBm}$ untuk uplink. Berdasarkan perhitungan nilai redaman link budget memenuhi standar, akan tetapi margin daya yang dihasilkan kecil. Hasil availability untuk telepon yang sudah mencapai target sebesar $95,39 \%$ dibulan September, availability untuk internet tidak mencapai target, karena banyak gangguan yang disebabkan oleh human error dan availability untuk IPTV sudah mencapai target sebesar $\mathbf{9 6 , 7 2 \%}$ di bulan Juli dan $97,97 \%$ di bulan Agustus.
\end{abstract}

Kata kunci: Availability, Jaringan FTTH, Link Budget, Triple Play

\section{Abstract}

FTTH is a network technology using fiber optic cable as the transmission medium. The FTTH network on indihome often gets interrupted. Therefore, this research was conducted by calculating the performance on the link budget parameter with 5 samples of customers and calculating availability with SLG (Service Level Guarantee) data for triple play services. Voice services are obtained from SLG data on the telephone, video services are obtained from SLG data on IPTV and data services are obtained from SLG data on the internet. Performance analysis uses the link budget method with the ITU-T G.984 standard where the sensitivity is $-28 \mathrm{dBm}$ and the availability is the minimum standard of PT. Telkom 95\%. The calculation results show that the Berkoh area which is the customer with the furthest distance from the 5 samples of receiving power calculations is obtained $(-24,014) \mathrm{dBm}$ for downlink and ($28,297) \mathrm{dBm}$ for uplink. The calculation of the power margin results in $3.986 \mathrm{dBm}$ for the downlink and $(-0.297)$ $\mathrm{dBm}$ for the uplink. Based on the calculation of the link budget attenuation value meets the standard, but the resulting power margin is small. Availability results for telephones that have reached the target of $95.39 \%$ in September, availability for internet has not reached the target, because many disturbances are caused by human error and availability for IPTV has reached the target of $96.72 \%$ in July and $97.97 \%$ in August.

Keywords: Availability, FTTH Network, Link Budget, Triple Play 


\section{Pendahuluan}

Perkembangan teknologi bidang internet seperti layanan berbasis IP dan konektivitas broadband membutuhkan bandwidth yang besar dan kecepatan tinggi untuk mendukung peningkatan pengiriman data. Hal tersebut mendorong perusahaan telekomunikasi untuk menawarkan layanan terbaik agar dapat menarik dan memberikan layanan atau jasa terbaik kepada pelanggan [1]. Layanan tersebut merupakan layanan konvergensi jaringan akses yang dikenal dengan layanan triple play. Layanan triple play sangat berkaitan dengan teknologi jaringan fiber optik. Teknologi fiber optik merupakan media yang tidak diragukan untuk menyediakan bandwidth yang besar, tidak dipengaruhi interferensi gelombang elektromagnetik, bebas korosi dan menyediakan redaman yang sangat kecil untuk transportasi data.

Terdapat empat macam arsitektur untuk mendukung jaringan fiber optik, salah satunya adalah Fiber To The Home (FTTH). FTTH merupakan teknologi jaringan dengan koneksi internet menggunakan kabel serat optik sebagai media transmisinya. Transmisi serat optik memiliki keunggulan dimana sangat mendukung pengiriman informasi triple play secara lebih efektif. Oleh karena itu PT Telkom sebagai salah satu perusahaan telekomunikasi terbesar di Indonesia telah memanfaatkan arsitektur FTTH untuk mendukung layanan triple play, layanan tersebut dikenal dengan Indihome Fiber. Arsitektur jaringan FTTH masih terdapat kekurangan yang menyebabkan sering terjadi gangguan pada layanan Indihome Fiber maka perlu dilakukan suatu perhitungan link budget dan availability. Hasil sebelumnya menunjukan bahwa jaringan FTTX di Purwokerto Timur sudah memenuhi standar kelayakan sistem berdasarkan perhitungan parameter link budget, rise time budget dan bit error rate dan splitter 1:4, 1:8 dan 1:16 [1]. Akan tetapi, penelitian tersebutterbatas pada perancangan dan simulasi.Oleh karena itu, pada penelitian ini penulis tertarik untuk melakukan pengukuran langsung dan perhitungan teoritis meggunakan data yang diperoleh dari PT. Telkom Indonesia Regional 4, Jateng Barat Selatan. Sehingga penelitian atau skripsi ini akan fokus pada "Analisis Performansi Jaringan Indihome Fiber Di Purwokerto" meliputi link budget dan availability.

\section{DASAR TEORI}

\section{A. Fiber Optik}

Fiber optik merupakan saluran transmisi atau sejenis kabel yang terbuat dari kaca atau plastik yang sangat halus dan lebih kecil dari sehelai rambut, dan dapat digunakan untuk mentransmisikan sinyal cahaya dari suatu tempat ke tempat lain. Sumber cahaya yang digunakan biasanya adalah laser atau LED. Kabel ini berdiameter lebih kurang 120 mikrometer. Cahaya yang ada di dalam serat optik tidak keluar karena indeks bias dari kaca lebih besar daripada indeks bias dari udara, karena laser mempunyai spektrum yang sangat sempit. Kecepatan transmisi serat optik sangat tinggi sehingga sangat bagus digunakan sebagai saluran komunikasi.

Bagian dari serat optik terdiri atas 3 bagian yaitu core, cladding dan buffer coating. Cladding adalah selubung dari core. Cladding mempunyai indek bias lebih rendah dari pada core akan memantulkan kembali cahaya yang mengarah keluar dari core kembali kedalam core lagi. Efisiensi dari serat optik ditentukan oleh kemurnian dari bahan penyusun gelas. Semakin murni bahan gelas, semakin sedikit cahaya yang diserap oleh serat optik.Dalam aplikasinya, serat optik yang biasa digunakan memiliki 3 mode, yaitu Singlemode step indeks, multimode step indeks, dan Multimode graded indeks [2]. Kelebihan dari single mode adalah memiliki performansi yang lebih tinggi dibandingkan dengan multimode yaitu pada penggunaan bandwidth dan nilai redaman. Memiliki diameter core yang lebih kecil, perambatan cahaya hanya satu berkas cahaya. Singlemode step indeks dapat digunakan pada transmisi jarak jauh dengan transmisi data untuk bit rate tinggi karena mampu mentransmisikan $10-40$ panjang gelombang. Jenis serat optik multimode memiliki keuntungan yaitu kemudahan ketika melakukan splicing karena memiliki diameter core yang besar. Dengan alasan yang sama, konektor digunakan untuk terminasi akhir dari serat optik untuk berbagai perangkat yang lebih murah. Dengan core, numerical aperture yang besar dan jarak link yang pendek,

Prinsip perambatan cahaya dalam serat optic terilustrasi dalam Gambar 1 berikut. 


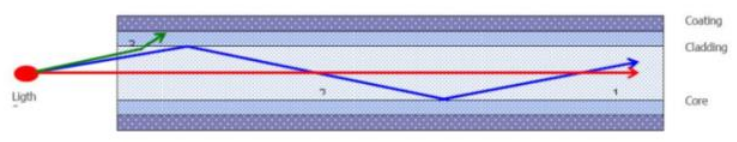

Gambar 1. Lintasan Cahaya Dalam Serat [3]

Terdapat tiga kemungkinan lintasan cahaya yang merambat di dalam serat. Kemungkinan pertama cahaya lurus sepanjang sumbu serat tanpa mengalami gangguan. Kedua, cahaya dapat mengalami refleksi karena memiliki sudut datang yang lebih besar dari sudut kritis dan akan merambat sepanjang serat melalui pantulan-pantulan. Atau cahaya akan mengalami refraksi dan tidak akan dirambatkan sepanjang serat karena memiliki sudut datang yang lebih kecil dari sudut kritis.

\section{B. Arsitektur Jaringan Lokal Akses Fiber}

Jaringan Lokal Akses Fiber (Jarlokaf) atau Optical Access Network adalah sekumpulan jaringan akses yang menggunakan secara bersama suatu antarmuka jaringan dan diimplementasikan menggunakan serat optik. Jarlokaf merupakan suatu solusi strategis bagi jaringan pelanggan namun sangat sensitif terhadap jenis teknologi. Keberadaan panduan dan ketepatan pemilihan teknologi sangat mempengaruhi kesuksesan kegiatan operasi dan perawatan, efektifitas investasi serta kemudahan menyediakan jasa-jasa baru.

Sistem Jarlokaf setidaknya memiliki 2 buah perangkat opto-elektronik, yaitu satu perangkat optoelektronik di sisi sentral dan satu perangkat opto-elektronik di sisi pelanggan. Lokasi perangkat optoelektronik di sisi pelanggan selanjutnya disebut Titik Konversi Optik (TKO). Secara praktis TKO berarti batas terakhir kabel optik ke arah pelanggan yang berfungsi sebagai lokasi konversi sinyal optik ke sinyal elektronik.

\section{Perangkat dalam Jaringan FTTH}

\section{OLT (Optical Line Terminal)}

Opticl Line Terminal (OLT) adalah suatu perangkat aktif yang berfungsi mengubah sinyal elektrik menjadi sinyal optik biasa disebut sebagai alat multiplex.

\section{ODC (Optical Distribution Cabinet)}

ODC adalah suatu perangkat pasif yang diinstalasi diluar STO bisa di lapangan (outdoor) dan juga bisa didalam ruangan atau di MDF Gedung HRB (indoor).

\section{ODP (Optical Distribution Point)}

ODP juga merupakan suatu perangkat pasif yang di instalasi diluar STO, bisa dilapangan (outdoor) dan juga bisa didalam ruangan (indoor), didalam gedung HRB.

\section{Optical Indoor Outlet (Roset)}

Roset merupakan perangkat pasif yang diletakan didalam rumah pelanggan, yang menjadi titik terminasi akhir dari kabel indoor fiber optic, kapasitas roset biasanya 1 atau 2 port.

\section{ONT (Optical Network Terminal)}

Optical Network Unit (ONU) dan Optical Network Terminal (ONT) adalah suatu perangkat aktif ( OptoElektik) yang dipasang disisi pelanggan

Tabel 1. Spesifikasi ONT [4]

\begin{tabular}{|l|c|c|}
\hline \multicolumn{1}{|c|}{ Parameter } & Spesifikasi & Unit \\
\hline Downlink Wavelength & 1490 & $\mathrm{~nm}$ \\
\hline Uplink Wavelength & 1310 & $\mathrm{~nm}$ \\
\hline Video Wavelength & 1550 & $\mathrm{~nm}$ \\
\hline Spectrum Width & 1 & $\mathrm{~nm}$ \\
\hline Downstream Rate & 2,4 & $\mathrm{Gbps}$ \\
\hline Upstream Rate & 1,2 & $\mathrm{Gbps}$ \\
\hline Optical Rise Time & 200 & $\mathrm{ps}$ \\
\hline
\end{tabular}




\section{Konektor}

Konektor merupakan salah satu material yang membangun jalur untuk GPON. Konektor adalah suatu material yang dipakai untuk menyambungkan core optik dengan cara mekanikal. Type konektor ada beberapa jenis yaitu [5]:

a. Fiber Connector (FC), konektor tipe FC dapat menyambungkan core optik dengan transmitter ataupun receiver. Konektor ini sangat cocok digunakan untuk jenis serat optik single mode karena mempunyai akurasi yang tinggi. Dalam pengaturannya konektor FC memiliki sistem drat ulir, sehingga tinggkat akurasi tidak akan mudah berubah.

b. Subscriber Connector (SC), konektor jenis SC dipakai untuk serat optik jenis single mode, yang memiliki sistem cabut pasang. Konektor SC bisa diatur dengan manual, konektor SC memiliki tingkat akurasi yang baik jika dipasang dengan perangkat lain.

c. Straig

d. ht Tip, konektor jenis ini dapat digunakan untuk serat optik jenis multimode maupun serat optik singlemode. Bentuk dari konektor Straight Tip tidak jauh beda dari konektor BNC.

\section{Splitter}

Passive Splitter (PS) adalah suatu perangkat pasif yang berfungsi untuk membagi informasi sinyal optic (gelombang cahaya). Tabel 2 merupakan tabel jenis splitter.

Tabel 2. Jenis Splitter [4]

\begin{tabular}{|c|c|}
\hline JENIS SPLITTER & BESAR REDAMAN \\
\hline $1: 02$ & $3,70 \mathrm{~dB}$ \\
\hline $1: 04$ & $7,25 \mathrm{~dB}$ \\
\hline $1: 08$ & $10,38 \mathrm{~dB}$ \\
\hline $1: 16$ & $14,10 \mathrm{~dB}$ \\
\hline $1: 32$ & $17,45 \mathrm{~dB}$ \\
\hline
\end{tabular}

Splitter yang akan digunakan ada 2 tipe yaitu splitter 1:4 dan splitter 1:8. Splitter 1:4 diletakkan di ODC sebanyak 2 buah, sedangkan splitter 1:8 diletakkan di ODP sebanyak 2 buah. Total splitter yang digunakan ada 7 buah terdiri dari 2 buah ada di STO, 2 buah di ODC, 2 buah di ODP dan 1 buah di roset.

\section{Teknologi Gigabit Passive Opticel Network (GPON)}

GPON adalah teknologi jaringan akses lokal fiber optik berbasis PON yang distandardisasi oleh ITU-T (ITU-T G.984 series). GPON adalah suatu teknologi akses yang dikategorikan sebagai broadband access berbasis kabel fiber optik. Pada GPON sebuah atau beberapa OLT interface sentral dengan jaringan fiber optik dihubungkan dengan beberapa ONU interface pelanggan dengan jaringan serat optik menggunakan pasif optical distribution network (ODN), seperti splitter, filter atau perangkat pasif optik lainnya. GPON mampu memberikan layanan dengan kecepatan 2.488 Gbps untuk downstream dan 1.244 Gbps untuk upstream.

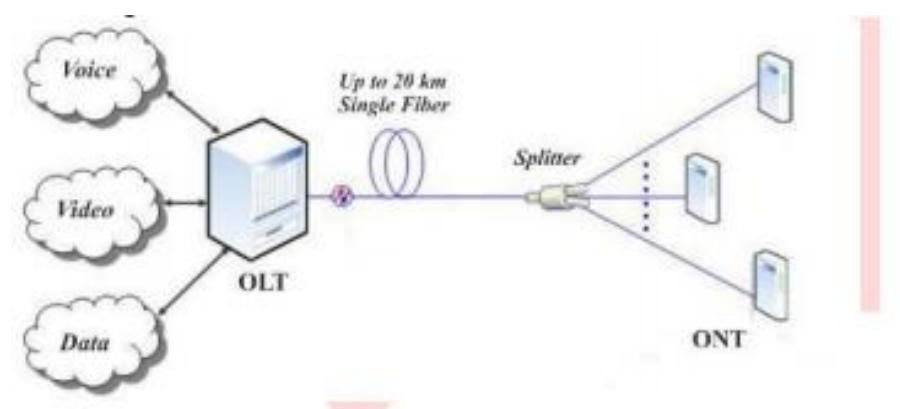

Gambar 2. Arsitektur GPON 
Gambar 2 menunjukkan prinsip kerja dari GPON. GPON memiliki cara kerja di mana ketika data atau sinyal dikirimkan dari OLT, maka ada bagian yang bernama splitter yang berfungsi untuk memungkinkan fiber optik tunggal dapat mengirim ke berbagai ONT. Untuk ONT sendiri akan memberikan data-data dan sinyal yang diinginkan oleh user. Pada prinsipnya passive optical network adalah sistem point-tomultipoint, dari fiber ke arsitektur premise network dimana unpowered optical splitter (splitter fiber) serat optik tunggal.

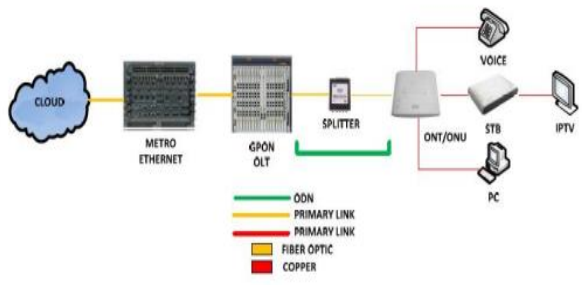

Gambar 3. Topologi GPON [6]

Metro Ethernet yang merupakan protocol transportasi data yang terhubung pada OLT menggunakan kabel fiber optik. Dapat dilihat pada Gambar 3 tersebut diatas dimana memperlihatkan topologi umum teknologi GPON dimana OLT terhubung langsung dengan MetroE [6]. Sinyal optik didistribusikan kearah ONU/ONT melalui passive splitter. ONU/ONT mentransmisikan sinyal elektrik untuk layanan triple play kepada user. Optical Distribution Network (ODN) adalah jaringan optik yang menghubungkan antara OLT dan ONU/ONT. ONU/ONT disambungkan Set Top Box (STB) untuk layanan IPTV, STB berfungsi untuk mengkonversikan digital signal menjadi analog signal yang berada disisi user untuk mengakses IPTV. sedangkan ONU/ONT langsung terhubung pada Personal Computer (PC) untuk layanan data (internet) dan telepon untuk layanan voice [7].

\section{E. Layanan Triple Play}

Terdapat banyak aplikasi yang dirancang dan disediakan melalui sebuah jaringan. Aplikasi Triple Play merupakan kombinasi dari beberapa tipe layanan yang memiliki berbagai parameter yang berbeda seperti bandwidth, tipe routing, QoS dan trafik simetri. Berikut 3 aplikasi layanan triple play [8].

1. Salah satu layanan data dalam layanan triple play adalah akses internet. Secara umum, perangkat kerja Internet adalah Internet Protocol Suite. Ukuran data untuk Internet bedasarkan MTU untuk IPv4 sekurang - kurangnya adalah 68 Bytes

2. Voice over Internet Protocol merupakan teknologi menyalurkan suara yang sudah diubah dan dikemas secara padat berupa paket data kedalam jaringan internet atau intranet melalui sebuah protocol (yaitu protokol TCP/IP). VoIP berarti menggunakan jaringan internet untuk melakukan pembicaraan suatu kanal suara analog dimampatkan menjadi $8-16 \mathrm{Kbps}$

3. IPTV adalah sebuah sistem yang digunakan untuk mengirim layanan televisi digital kepada subscriber dalam system tersebut. Pengiriman sinyal digital televisi tersebut memungkinkan diselenggarakan menggunakan Internet Protocol melewati sebuah koneksi broadband yang digunakan pada jaringan dengan kualitas yang lebih baik daripada akses internet public agar kualitas pelayanan terjamin

\section{F. Layanan Indihome Fiber}

Indihome merupakan layanan Triple Play dari Telkom yang terdiri dari telepon rumah, internet on fiber atau high speed internet dan use tv kabel (IPTV) beserta beberapa fitur tambahan seperti Indihome View, MeIOn dan Trend Micro Security System. Layanan indihome ini diberikan melalui media fiber optik untuk memenuhi kebutuhan masyarakat di Indonesia dan hampir semua sudah diganti dengan jaringan fiber optik. Semua ini untuk meningkatkan kualitas layanan Triple Play [18]. 


\section{G. Performansi Jaringan}

Perhitungan link power budget untuk mengetahui batasan redaman total yang diijinkan antara daya keluaran pemancar dan sensitivitas penerima. Perhitungan ini dilakukan berdasarkan standarisasi ITU-T G.984. Link Budget digunakan untuk mengetahui layak atau tidaknya jaringan FTTH diimplementasikan pada jaringan sebenarnya [9]. Bentuk Persamaan untuk perhitungan redaman total pada link power dan perhitungan margin daya adalah [4]:

$$
\begin{aligned}
& a_{\text {tot }}=L_{\cdot} \cdot a_{\text {serat }}+N_{c} \cdot a_{c}+N_{s} \cdot a_{s}+a_{s p} \\
& M=\left(P_{t}-P_{r}\right)-a_{\text {tot }}-M_{s}
\end{aligned}
$$

Dengan: $\mathrm{P}_{\mathrm{t}}=$ daya keluaran sumber optik $(\mathrm{dBm}), \mathrm{P}_{\mathrm{r}}=$ daya terima detektor $(\mathrm{dBm}), \mathrm{M}_{\mathrm{s}} \quad$ = safety margin, sekitar 6-8 dB, = redaman total sistem $(\mathrm{dB}), \mathrm{L}=$ panjang serat optik $(\mathrm{km}), \mathrm{a}_{\mathrm{tot}}=$ redaman total sistem $(\mathrm{dB})$, $\mathrm{a}_{\mathrm{c}}=$ redaman Konektor $(\mathrm{dB} /$ buah $), \mathrm{a}_{\mathrm{s}}=$ redaman sambungan $(\mathrm{dB} /$ sambungan $), \mathrm{a}_{\text {serat }}=$ redaman serat optik $(\mathrm{dB} / \mathrm{Km}), \mathrm{N}_{\mathrm{s}}=$ Jumlah sambungan, $\mathrm{N}_{\mathrm{c}}=$ Jumlah konektor, $\mathrm{a}_{\mathrm{sp}}=$ Redaman Splitter $(\mathrm{dB})$.

Margin daya disyaratkan harus memiliki nilai lebih dari 0 (nol). Margin daya adalah daya yang masih tersisa dari power transmit setelah dikurangi dari loss selama proses pentransmisian, pengurangan dengan nilai safety margin dan pengurangan dengan nilai sensitivitas receiver.

Availability adalah prosentase waktu yang menunjukkan kanal komunikasi pada sistem siap untuk beroperasi. Pada perhitungan availability menggunakan perhitungan jumlah SLG complitedan total gangguan. SLG comply adalah jumlah gangguan yang sudah diperbaiki. Total gangguan adalah jumlah keseluruhan gangguan dari gangguan yang sudah diperbaiki sampai gangguan dalam tahap proses perbaikan. Dengan rumus sebagai berikut:

$$
\text { AV }=\frac{\text { Uptime }}{\text { Uptime }+ \text { Downtime }}\left[\frac{\text { Jumlah SLG Comply }}{\text { Total Gangguan }}\right] \times 100 \%
$$

Dengan $A V$, SLG comply, dan Total Gangguan adalah Availability, Jumlah SLG gangguan yang sudah tercover, dan Jumlah seluruh gangguan.

\section{Metode Penelitian}

Proses penelitian dimulai dengan menentukan lokasi untuk dilakukan analisis. Pemilihan lokasi ini dilihat dari trafik data tertinggi di PT. Telkom Indonesia Regional 4, Jateng Barat Selatan. Dipilihlah lokasi kota Purwokerto untuk dilakukannya analisis. Selanjutnya mengumpulkan data-data indihome fiber dengan data meliputi konfigurasi FTTH, jarak setiap link, data gangguan selama 3 bulan, jenis serat optik yang digunakan dan materi-materi yang terkait. Data-data yang digunakan untuk menghitung link budget, availability, dan pelayanan gangguan. Flowchart proses penelitian ditunjukkan pada Gambar 4. 


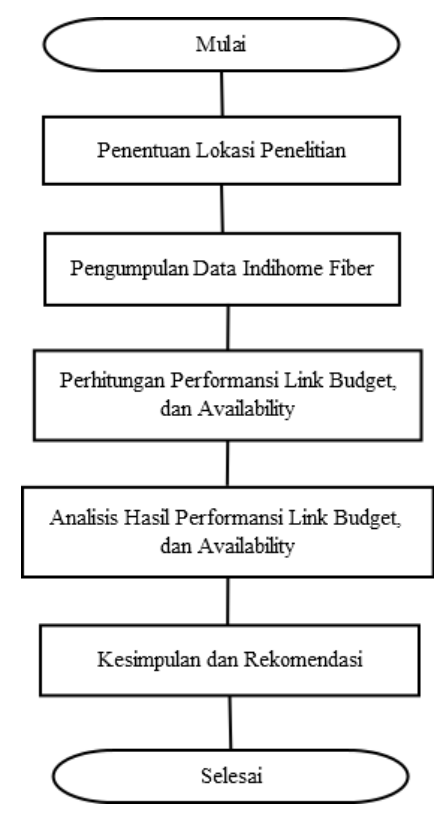

Gambar 4. Flowchart Proses Penelitian

Tabel 3 dan 4 berikut adalah spesifikasi perangkat dalam jaringan FTTH.

Tabel 3. Spesifikasi OLT

\begin{tabular}{|l|l|c|}
\hline \multicolumn{1}{|c|}{ Parameter } & \multicolumn{1}{|c|}{ Spesifikasi } & Unit \\
\hline Optical Transmit Power & 5 & $\mathrm{dBm}$ \\
\hline Downlink Wavelength & 1490 & $\mathrm{~nm}$ \\
\hline Uplink Wavelength & 1310 & $\mathrm{~nm}$ \\
\hline Video Wavelength & 1550 & $\mathrm{~nm}$ \\
\hline Spectrum Width & 1 & $\mathrm{Nm}$ \\
\hline Downstream Rate & 2,4 & $\mathrm{Gbps}$ \\
\hline Upstream Rate & 1,2 & $\mathrm{Gbps}$ \\
\hline Optical Rise Time & 160 & $\mathrm{Ps}$ \\
\hline
\end{tabular}

Tabel 4. Spesifikasi ONT

\begin{tabular}{|l|l|c|}
\hline \multicolumn{1}{|c|}{ Parameter } & \multicolumn{1}{c|}{ Spesifikasi } & Unit \\
\hline Downlink Wavelength & 1490 & $\mathrm{Nm}$ \\
\hline Uplink Wavelength & 1310 & $\mathrm{Nm}$ \\
\hline Video Wavelength & 1550 & $\mathrm{Nm}$ \\
\hline Spectrum Width & 1 & $\mathrm{Nm}$ \\
\hline Downstream Rate & 2,4 & $\mathrm{Gbps}$ \\
\hline Upstream Rate & 1,2 & $\mathrm{Gbps}$ \\
\hline Optical Rise Time & 200 & Ps \\
\hline
\end{tabular}

Serat optik yang digunakan adalah yang sesuai dengan standar ITU-T G.652.D dan G.657.A. Serat optik ITU-T G.652.D digunakan untuk kabel feeder dan kabel distribusi. Rugi-rugi serat optik ITU-T G.652.D dan G.657.A pada panjang gelombang $1310 \mathrm{~nm}$ sebesar $\leq 0,35 \mathrm{~dB} / \mathrm{Km}$ dan pada panjang gelombang 1490 $\mathrm{nm}$ sebesar $\leq 0,28 \mathrm{~dB} / \mathrm{Km}$. Konektor yang digunakan adalah konektor SC. Konektor SC digunakan pada bagian OLT sampai ONT memakai konektor SC/UPC dengan loss 0,25 dB. Terdapat 2 buah konektoryang terletak pada Roset dan ODP. Sambungan yang dilakukan dari OLT sampai ONT menggunakan sambungan permanen (sambungan fusi). Rugi-rugi dari sambungan sebesar 0,10 dB. Sambungan terdapat di kabel 
feeder, kabel distribusi, dan kabel drop. Splitter yang akan digunkan ada 2 tipe yaitu splitter 1:4 dan splitter 1:8. Splitter 1:4 dengan loss 7,25 dB diletakkan di ODC, sedangkan splitter 1:8 dengan loss 10,38 dB diletakkan di ODP. Total splitter yang digunakan ada 7 buah terdiri dari 2 buah ada di STO, 2 buah di ODC, 2 buah di ODP, dan 1 buah di roset.

Data-data yang digunakan dalam perhitungan link power budget yang menghitung daya penerima disisi pelanggan terdapat pada tabel 5, antara lain:

Tabel 5. Data Untuk Link Power Budget

\begin{tabular}{|l|l|}
\hline \multicolumn{1}{|c|}{ Parameter } & \multicolumn{1}{c|}{ Keterangan } \\
\hline $\mathrm{Pt}$ & $5 \mathrm{dBm}$ \\
\hline $\mathrm{Pr}$ & $-28 \mathrm{dBm}$ \\
\hline aserat G.652.D $(1310 / 1490)$ & $(0,35 ; 0,28) \mathrm{dB} / \mathrm{Km}$ \\
\hline aserat G.657.A $(1310 / 1490)$ & $(0,35 ; 0,28) \mathrm{dB} / \mathrm{Km}$ \\
\hline as di kabel Feeder & $0,10 \mathrm{~dB} /$ splice \\
\hline as di kabel Distribusi & $0,10 \mathrm{~dB} /$ splice \\
\hline as di kabel Drop & $0,10 \mathrm{~dB} /$ splice \\
\hline Redaman Konektor jenis SC/UPC & $0,25 \mathrm{~dB} /$ connector \\
\hline Redaman Splitter $1: 4$ & $7,25 \mathrm{~dB}$ \\
\hline Redaman Splitter 1:8 & $10,38 \mathrm{~dB}$ \\
\hline Jumlah sambungan & $5 \mathrm{buah}$ \\
\hline Jumlah Konektor & $7 \mathrm{buah}$ \\
\hline Margin Daya & $>0 \mathrm{~dB}$ \\
\hline
\end{tabular}

Availability dihitung dengan menggunakan data SLG. Service Level Guarantee (SLG) adalah janji Telkom kepada customer mengenai maximum resolution time penanganan gangguan jaringan indihome fiber mencakup deskripsi layanan, waktu layanan dan penalty menggunakan Persamaan 3.

\section{Hasil Penelitian}

Secara umum penelitian ini membahas performansi suatu jaringan FTTH yang di aplikasikan untuk layanan indihome fiber di Purwokerto. Penelitian ini bertujuan untuk menganalisis performansi berdasarkan parameter perngukuran link budget, dan availability. Hasil performansi diperoleh dengan data dari PT. Telkom Indonesia Regional 4, Jateng Barat Selatan area Purwokerto. Pada perhitungan digunakan rumusrumus persamaan untuk mencari nilai dari link budget, dan availability. Parameter perhitungan Link Budget dapat dilihat pada Tabel 6. Berikut adalah perhitungan link budget STO-ONT Al-Azhar, Pandak Baturraden.

Tabel 6. Parameter Perhitungan Link Budget

\begin{tabular}{|l|l|}
\hline \multicolumn{1}{|c|}{ Parameter } & \multicolumn{1}{c|}{ Keterangan } \\
\hline Pt & $5 \mathrm{dBm}$ \\
\hline Panjang Serat Optik & $8,563 \mathrm{Km}$ \\
\hline aserat G.652.D $(1310 / 1490)$ & $(0,35 ; 0,28) \mathrm{dB} / \mathrm{Km}$ \\
\hline aserat G.657.A (1310/1490) & $(0,35 ; 0,28) \mathrm{dB} / \mathrm{Km}$ \\
\hline Redaman Sambungan & $0,10 \mathrm{~dB} /$ splice \\
\hline Redaman Konektor jenis SC/UPC & $0,25 \mathrm{~dB} /$ connector \\
\hline Redaman Splitter 1:4 & $7,25 \mathrm{~dB}$ \\
\hline Redaman Splitter 1:8 & $10,38 \mathrm{~dB}$ \\
\hline Jumlah sambungan & 5 buah \\
\hline Jumlah Konektor & 7 buah \\
\hline
\end{tabular}




\section{$\underline{\text { Downlink }}$}

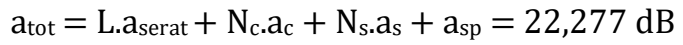

Sehingga untuk perhitungan margin daya adalah sebagai berikut :

$$
\begin{aligned}
& \operatorname{Pr}=P_{t}-a_{t o t}-M_{s}=-23,277 d B m \\
& M=\left(P_{t}-P_{r}\right)-a_{t o t}-M_{s}=4,723 d B
\end{aligned}
$$

\section{$\underline{\text { Uplink }}$}

$$
a_{\text {tot }}=L \cdot a_{s e r a t}+N_{c} \cdot a_{c}+N_{s} \cdot a_{s}+a_{s p}=22,877 d B
$$

Sehingga untuk perhitungan margin daya adalah sebagai berikut :

$\operatorname{Pr}=\mathrm{P}_{\mathrm{t}}-\mathrm{a}_{\mathrm{tot}}-\mathrm{M}_{\mathrm{s}}=-27,377 \mathrm{dBm}$

$M=\left(P_{t}-P_{r}\right)-a_{\text {tot }}-M_{s}=0,623 d B$

Berikut adalah perhitungan availability gangguan telepon

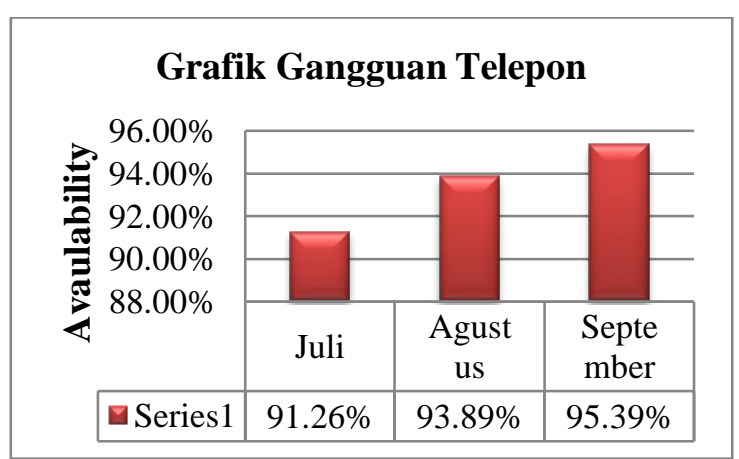

Gambar 5. Grafik SLG Telepon

Grafik tersebut diatas menunjukan besarnya prosentase availability pada telepon yang diperoleh dari data SLG selama bulan Juli, Agustus, dan September tahun 2016 (Gambar 5). Dimana SLG adalah jaminan kepada pelanggan untuk penanganan gangguan pada jaringan. Prosentase availability yang di peroleh bulan Juli sebesar 91,26\%, bulan Agustus sebesar 93,89\%, dan bulan September sebesar 95,39\%.

Perhitungan availability telephone dibulan Juli dengan menggunakan persamaan berikut :

$$
\mathrm{Av}=\left[\frac{\text { Jumlah SLG Comply }}{\text { Total Gangguan }}\right] \times 100 \%
$$

Berikut adalah perhitungan availability gangguan internet

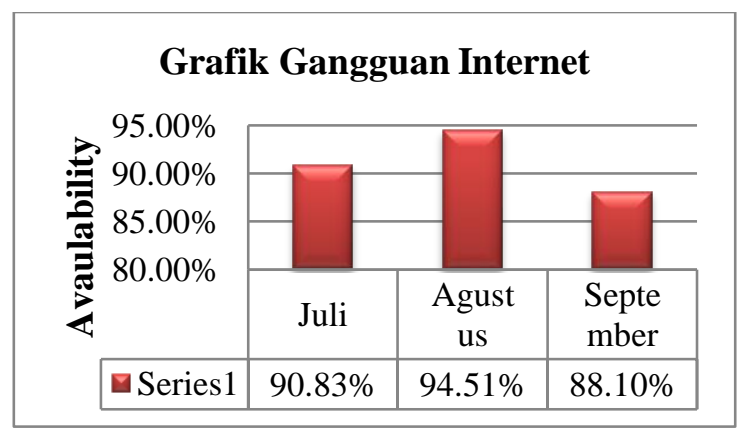

Gambar 6. Grafik SLG Internet 
Grafik tersebut diatas menunjukan besarnya prosentase availability pada internet yang diperoleh dari data SLG selama bulan Juli, Agustus, dan September tahun 2016 (Gambar 6). Dimana SLG adalah jaminan kepada pelanggan untuk penanganan gangguan pada jaringan. Prosentase availability yang di peroleh bulan Juli sebesar 90,83\%, bulan Agustus sebesar 94,51\%, dan bulan September sebesar 94,09\%.

Berikut adalah perhitungan availability gangguan IPTV

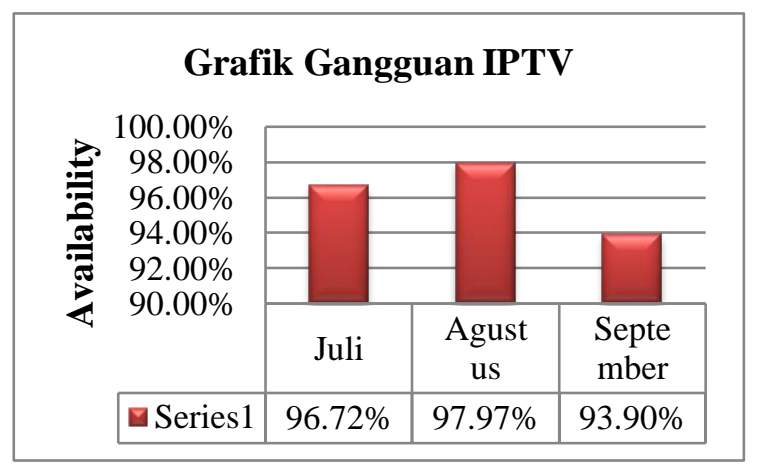

Gambar 7. Grafik SLG IPTV

Grafik pada Gambar 7 menunjukan besarnya prosentase availability pada IPTV yang diperoleh dari data SLG selama bulan Juli, Agustus, dan September tahun 2016. Dimana SLG adalah jaminan kepada pelanggan untuk penanganan gangguan pada jaringan. Prosentase availability yang di peroleh bulan Juli sebesar 96,72\%, bulan Agustus sebesar 97,97\%, dan bulan September sebesar 93,90\%.

Pada parameter link budget melakukan perhitungan dengan rumus. Berikut adalah hasil perhitungan yang dirangkum dalam Tabel 7.

Tabel 7. Hasil Perhitungan Link Budget

\begin{tabular}{|l|c|c|c|c|}
\hline \multirow{2}{*}{ Link } & \multicolumn{2}{|c|}{ Perhitungan (dBm) } & \multicolumn{2}{c|}{ Margin Daya (dBm) } \\
\cline { 2 - 5 } & $\begin{array}{c}\text { Downlin } \\
\mathbf{k}\end{array}$ & Uplink & $\begin{array}{c}\text { Downlin } \\
\mathbf{k}\end{array}$ & Uplink \\
\hline STO - Pandak Baturraden & $-23,277$ & $-27,377$ & 4,723 & 0,623 \\
\hline STO - Bancar Kembar & $-21,949$ & $-25,717$ & 6,051 & 2,283 \\
\hline STO - Berkoh & $-24,014$ & $-28,297$ & 3,986 & $-0,297$ \\
\hline STO - Sokaraja & $-22,575$ & $-26,499$ & 5,425 & 1,501 \\
\hline STO - Teluk & $-22,673$ & $-26,622$ & 5,327 & 1,378 \\
\hline
\end{tabular}

Parameter link budget menunjukkan perbedaan level daya yang diperbolehkan antara pemancar dan penerima. Berdasarkan hasil perhitungan pada jarak $8,563 \mathrm{~km}$ beralamat di pandak baturraden menunjukan nilai pada daya terima untuk downlink $(-23,277) \mathrm{dBm}$ dan uplink $(-27,377) \mathrm{dBm}$. Nilai tersebut memenuhi standar ITU-T G.984. Perhitungan dengan jarak 3,82 km beralamat di bancar kembar menunjukan nilai (21,949) dBm untuk downlink dan (-25,717) dBm untuk uplink. Perhitungan dengan jarak $11,193 \mathrm{~km}$ beralamat di Berkoh menunjukan hasil $(-24,014) \mathrm{dBm}$ untuk downlink dan $(-28,297) \mathrm{dBm}$ untuk uplink. Perhitungan dengan jarak 6,05 km beralamat di Sokaraja menunjukan nilai daya terima untuk downlink ($22,575) \mathrm{dBm}$ dan untuk uplink $(-26,499) \mathrm{dBm}$. Perhitungan dengan jarak 6,406 km beralamat di Perumahan Tiara Permai 2 menunjukkan nilai daya terima untuk downlink $(-22,673) \mathrm{dBm}$ dan untuk uplink $(-26,622)$ $\mathrm{dBm}$. Secara garis besar nilai daya terima ke lima sample tersebut diatas memenuhi standar sensitivitas detektor optik yang bernilai $-28 \mathrm{dBm}$. Sedangkan nilai performansi link budget bisa dilihat juga dari margin sistem. Margin diperlukan untuk mengantisipasi adanya perubahan parameter komponen karena usia operasi sehingga menyebabkan degradasi. Margin harus menunjukkan nilai positif. Margin memiliki nilai minimal $6 \mathrm{~dB}$. Berdasarkan perhitungan link budget maka didapat hasil margin daya di STO ke Pandak Baturraden untuk downlink 4,723 dB dan uplink 0,623 dB. Perhitungan di STO ke Bancar Kembar 6,051 $\mathrm{dB}$ untuk downlink dan 2,283 dB untuk uplink. Perhitungan di STO ke Berkoh menunjukan nilai untuk downlink 3,986 dB dan untuk uplink $(-0,297) \mathrm{dB}$, link uplink Berkoh - STO jika dilihat dari nilai margin 
daya berada pada posisi yang tidak layak pakai, akan tetapi dilihat berdasarkan daya terima pada gambar 3 link tersebut masih dalam posisi aman karena masuk dalam toleransi penalti uplink sebesar 0,5 dB. Perhitungan di STO ke Sokaraja menunjukan nilai 5,425 dB untuk downlink dan 1,501 dB untuk uplink. Perhitungan di STO ke Teluk menunjukan nilai untuk downlink 5,327 dB dan 1,378 dB untuk uplink. Secara garis besar nilai daya terima berdasarkan perhitungan link budget memenuhi standar ITU-T G.984. Akan tetapi untuk perhitungan margin sistem yang diperoleh jarak yang paling dekat dengan STO hasil perhitungan margin daya lebih bagus dari yang lain. Dapat diartikan bahwa pada hasil margin daya tersebut bagus untuk mengcover jika terjadi gangguan. Secara umum semua nilai margin daya yang dihasilkan dapat mengcover gangguan. Akan tetapi, nilai yang $\leq 6 \mathrm{~dB}$ yang baik untuk digunakan.

Berikut adalah hasil perhitungan availability pada telepon

Tabel 8. SLG Gangguan Telepon

\begin{tabular}{|c|c|c|c|}
\hline \multicolumn{3}{|c|}{ JULI } \\
\hline SLG COMPLY & SLG NOT COMPLY & TOTAL TIKET CLOSE & SLG COMPLY(\%) \\
\hline 115 & 11 & 126 & $91,26 \%$ \\
\hline \multicolumn{4}{|c|}{ AUGUSTUS } \\
\hline SLG COMPLY & SLG NOT COMPLY & TOTAL TIKET CLOSE & SLG COMPLY(\%) \\
\hline 200 & 13 & 213 & $93,89 \%$ \\
\hline \multicolumn{4}{|c|}{ SEPTEMBER } \\
\hline SLG COMPLY & SLG NOT COMPLY & TOTAL TIKET CLOSE & SLG COMPLY(\%) \\
\hline 207 & 10 & 217 & $95,39 \%$ \\
\hline
\end{tabular}

Berikut adalah hasil perhitungan availability pada internet

Tabel 9. SLG Gangguan Internet

\begin{tabular}{|c|c|c|c|}
\hline \multicolumn{4}{|c|}{ JULI } \\
\hline SLG COMPLY & SLG NOT COMPLY & TOTAL TIKET CLOSE & SLG COMPLY(\%) \\
\hline 119 & 12 & 131 & $90,83 \%$ \\
\hline \multicolumn{4}{|c|}{ AUGUSTUS } \\
\hline SLG COMPLY & SLG NOT COMPLY & TOTAL TIKET CLOSE & SLG COMPLY(\%) \\
\hline 224 & 13 & 237 & $94,51 \%$ \\
\hline \multicolumn{4}{|c|}{ SEPTEMBER } \\
\hline SLG COMPLY & SLG NOT COMPLY & TOTAL TIKET CLOSE & SLG COMPLY(\%) \\
\hline 200 & 27 & 227 & $88,10 \%$ \\
\hline
\end{tabular}

Berikut adalah hasil perhitungan availability pada IPTV

Tabel 10. SLG Gangguan IPTV

\begin{tabular}{|c|c|c|c|}
\hline \multicolumn{3}{|c|}{ JULI } \\
\hline SLG COMPLY & SLG NOT COMPLY & TOTAL TIKET CLOSE & SLG COMPLY(\%) \\
\hline 177 & 6 & 183 & $96,72 \%$ \\
\hline \multicolumn{3}{|c|}{ AUGUSTUS } \\
\hline SLG COMPLY & SLG NOT COMPLY & TOTAL TIKET CLOSE & SLG COMPLY(\%) \\
\hline 97 & 2 & 99 & $97,97 \%$ \\
\hline \multicolumn{4}{|c|}{ SEPTEMBER } \\
\hline SLG COMPLY & SLG NOT COMPLY & TOTAL TIKET CLOSE & SLG COMPLY(\%) \\
\hline 185 & 12 & 197 & $93,90 \%$ \\
\hline
\end{tabular}

Service Level Guarantee (SLG) adalah janji Telkom kepada customer mengenai maximum resolution time penanganan gangguan jaringan indihome fiber mencakup deskripsi layanan, waktu layanan dan penalti [2]. Pelayanan SLG diberikan dengan penanganan gangguan batas maximum waktu 3 hari, apabila lewat dari 3 hari maka pihak Telkom akan memberikan garansi seperti bebas biaya selama 1 bulan. Penanganan gangguan SLG dinyatakan dalam persen (\%) dan penanganan gangguan dinyatakan bagus jika mencapai 
95\% sampai dengan $100 \%$. Dari tabel 7 SLG gangguan pada telepon dari bulan Juli, Agustus, dan September dapat dilihat bahwa performansi yang di berikan untuk bulan Juli masih kurang bagus karena kurang dari 95\%. Untuk bulan Agustus masih kurang bagus karena kurang dari 95\%. Saat di bulan September sudah bagus karena sudah mencapai 95\%. Hal ini dikarenakan gangguan yang terjadi pada telepon berupa gangguan administrasi dan port yang terhubung ke telepon.

Dari tabel 9 SLG gangguan pada internet dari bulan Juli, Agustus, dan September dapat dilihat bahwa performansi yang di berikan untuk bulan Juli masih kurang bagus karena kurang dari 95\%. Untuk bulan Agustus masih kurang bagus karena kurang dari 95\%. Saat di bulan September kurang bagus karena tidak mencapai $95 \%$. Hal ini dikarenakan gangguan yang terjadi pada internet berupa gangguan administrasi dan kabel fiber optik yang terhubung.

Dari tabel 10 SLG gangguan pada IPTV dari bulan Juli, Agustus, dan September dapat dilihat bahwa performansi yang di berikan untuk bulan Juli sudah bagus karena lebih dari batas minimum 95\%. Untuk bulan Agustus sudah bagus karena lebih dari 95\%. Saat di bulan September kurang bagus karena tidak mencapai $95 \%$. Hal ini dikarenakan gangguan yang terjadi pada IPTV berupa gangguan administrasi, STB, setting ulang, dan port rusak.

\section{KESIMPULAN}

Berdasarkan perhitungan link budget downlink dan uplink dengan jarak 11,193 km dari STO yang merupakan jarak terjauh dari 5 sample beralamat di Berkoh, daya terima $(-24,014) \mathrm{dBm}$ untuk downlink dan $(-28,297) \mathrm{dBm}$ untuk uplink. Perhitungan margin daya diperoleh 3,986 dB untuk downlink dan $(-0,297)$ dB untuk uplink. Menunjukkan jaringan sudah memenuhi standar untuk nilai redaman pada link budget. Akan tetapi nilai margin yang dihasilkan kecil khususnya untuk uplink masih buruk. Berdasarkan perhitungan margin sistem rata-rata masih kecil. Sehingga menyebabkan prosentase gangguan pada SLG triple play sebagian besar belum mencapai target. Hal itu disebabkan karena jika ada gangguan pada link jaringan FTTH yang terlalu banyak margin sistem nya belum bisa mengcover jaringan tersebut. Berdasarkan hasil performansi prosentase SLG Gangguan pada Telepon bulan Juli 91,26\%, bulan Agustus 93,89\% dan bulan September 95,39\%. Dari hasil prosentase dapat ditarik bahwa performansi yang baik dari 3 bulan tersebut ada di bulan September. Gangguan yang sering terjadi adalah pesawat telepon pelanggan rusak, mengganti kabel RJ 11, dan kuota paket pelanggan habis. Berdasarkan hasil performansi prosentase SLG Gangguan pada Internet bulan Juli 90,83\%, bulan Agustus 94,51\% dan bulan September $88,10 \%$. Dari hasil prosentase dapat ditarik bahwa performansi dari 3 bulan tersebut tidak ada yang memenuhi target disebabkan masih ada gangguan belum tercover. Total gangguan 595 sedangkan gangguan masih ada 52 yang belum tercover. Berdasarkan hasil performansi prosentase SLG Gangguan pada IPTV bulan Juli 96,72\%, bulan Agustus 97,97\% dan bulan September 93,90\%. Dari hasil prosentase dapat ditarik bahwa performansi dari 3 bulan tersebut hanya di bulan September yang tidak mencapai target hal ini disebabkan karena human error.

\section{REFERENSI}

[1] T. C. Widianto, Simulasi dan analisis jaringan Fiber To The X (FTTX) Menggunakan Teknologi Gigabit Passive Optical Network (GPON) : Purwokerto Timur. 2017.

[2] F. P. D. Nidia, Analisis performansi Dense Wavelength Division Multiplexing jaringan backbone ring Jawa Tengah. Banyumas: IT-Telkom Purwokerto, 2017.

[3] D. Prasetya, Serat Optik. Palembang: Fakultas Ilmu Komputer Universitas Sriwijaya, 2009.

[4] B. Dermawan, I. Santoso, and T. Prakoso, "Analisis Jaringan Ftth (Fiber To the Home) Berteknologi Gpon (Gigabit Passive Optical Network)," Transmisi, vol. 18, no. 1, pp. 30-37-37, 2016.

[5] K. I. Lestari, Analisis Transmisi Upstream-Downstream Jaringan FTTH menggunakan Teknologi GPON: Studi Kasus di PT.Telkom Akses Purwokerto. Banyumas: IT-Telkom Purwokerto, 2017.

[6] M. R. M. Siahaan, Perancangan Jaringan Akses Fiber To The Home (FTTH) Menggunakan Teknologi Gigabit Passive Optical Network (GPON) di Perumahan Setra Duta Bandung. Bandung: Universitas Telkom, 2012.

[7] A. V. Putri, D. A. Y. Putri, and A. P. Adi, Analisa Implementasi GPON dan MSAN untuk Layanan Triple Play pada "KOTA 2 ARNET KOTA" PT Telkom Indonesia. Jakarta: Universitas Bina Nusantara, 2012.

[8] D. Aryanta, “Analisis Perbandingan Kinerja Layanan Triple Play pada Jaringan IP dan MPLS Menggunakan NS2," J. Inform Itenas, vol. 4, no. 1, pp. 25-37, 2013.

[9] M. I. Yanuardin, S. D. Ryana, and M. R. Rosmiati, "Perancangan Jaringan Ftth (Fiber To the Home)," e-Proceeding Appl. Sci., vol. 2, no. 1, pp. 325-331, 2016. 